\title{
Assessment of the probiotic potential of lactic acid bacteria isolated from kefir grains: evaluation of adhesion and antiproliferative properties in in vitro experimental systems
}

\author{
Ioanna Mantzourani ${ }^{1} \cdot$ Pelagia Chondrou ${ }^{2} \cdot$ Christos Bontsidis $^{1} \cdot$ Kyriaki Karolidou $^{2} \cdot$ Antonia Terpou $^{3}$. \\ Athanasios Alexopoulos ${ }^{1} \cdot$ Eugenia Bezirtzoglou $^{1} \cdot$ Alex Galanis $^{2} \cdot$ Stavros Plessas $^{1}$
}

Received: 21 November 2018 / Accepted: 19 March 2019 / Published online: 10 April 2019

(C) Università degli studi di Milano 2019

\begin{abstract}
The main objective of this study was to isolate lactic acid bacteria from kefir grains and investigate their probiotic potential. In this study, 48 bacterial strains were isolated from kefir grains, whereas 39 strains were categorized to the genus Lactobacillus. Evaluation of the probiotic potential of the isolated stains was performed, including resistance to low $\mathrm{pH}$, tolerance to pepsin, pancreatin and bile salts, and antibiotic resistance. In addition, evaluation of adhesion and antiproliferative properties in in vitro experimental systems was also conducted. Strains SP2 and SP5 that displayed the best performance in the conducted in vitro tests were selected for further studies. Firstly, genotypic identification of the two strains was performed by partial 16S rRNA gene sequencing, BLAST analysis, and species-specific multiplex PCR assay. The two strains were confirmed to be Pediococcus pentosaceus SP2 and Lactobacillus paracasei SP5. Then, the adhesion properties of the two strains were examined in vitro. Both strains displayed substantial adherence capacity to HT-29 human colon cancer cells. Moreover, a significant decrease of HT-29 cell growth after treatment with viable P. pentosaceus SP2 or L. paracasei SP5 was recorded. In addition, downregulation of antiapoptotic genes and over-expression of cell cycle-related genes was recorded by real-time PCR analysis. Treatment with conditioned media of the two strains also caused significant reduction of cancer cell proliferation in a time- and concentrationdependent manner. P. pentosaceus SP2 and L. paracasei SP5 displayed the best probiotic properties that exerted substantial adherence on human colon cancer cells as well as significant anti-proliferative properties.
\end{abstract}

Keywords Probiotics $\cdot$ Lactobacillus $\cdot$ Kefir $\cdot$ Adhesion $\cdot$ Anti-proliferation $\cdot$ Colon

Ioanna Mantzourani and Pelagia Chondrou contributed equally to this work.

Electronic supplementary material The online version of this article (https://doi.org/10.1007/s13213-019-01467-6) contains supplementary material, which is available to authorized users.

Stavros Plessas

splessas@agro.duth.gr

1 Laboratory of Microbiology, Biotechnology and Hygiene, Faculty of Agricultural Development, Democritus University of Thrace, 68200 Orestiada, Greece

2 Department of Molecular Biology and Genetics, Democritus University of Thrace, 68100 Alexandroupolis, Greece

3 Food Biotechnology Group, Section of Analytical Environmental and Applied Chemistry, Department of Chemistry, University of Patras, 26500 Patras, Greece

\section{Introduction}

Probiotics are defined as health-promoting bacteria. Lactobacillus species, such as Lactobacillus casei, L. paracasei, L. rhamnosus, and L. plantarum, are among the most common probiotic bacteria, which are used for the production of many dairy and non-dairy fermented food products (Granato et al. 2010; Rivera-Espinoza and Gallardo-Navarro 2010). Probiotic foods must contain an adequate amount (at least $10^{6} \mathrm{CFU} / \mathrm{g}$ ) of live microorganisms (Weese and Martin 2011), although recent studies aim towards the development of novel functional food products containing either inactivated cells or cell extracts (Howarth and Wang 2013). The healthpromoting properties of probiotics were originally described by the Russian immunologist, Elie Metchnikoff, and presented in his book "The prolongation of life" published in 1907. Nowadays, several studies have demonstrated that probiotics may be successful against several digestive disorders, such as 
the irritable bowel disease (Del Carmen et al. 2011), antibioticassociated diarrhea (Szajewska and Kołodziej 2015), and the necrotizing enterocolitis (Deshpande et al. 2010). In addition, probiotics may also have a positive impact against colorectal cancer prevention. They act through various molecular and cellular mechanisms that include alteration of the intestinal microflora, adhesion to colon cancer cells, and anti-proliferative activity (Bermudez-Brito et al. 2012).

The beneficial effects of probiotic bacteria have been considered to be strain-specific. Thus, different bacterial strains of the same species may induce completely different effects on the host (Campana et al. 2017). For that reason, a case-by-case approach should be followed to study the specific properties of individual strains and evaluate their potential positive effect on health. In addition, an elegant study has demonstrated recently that probiotic efficacy may also be person-specific and dependent on the host gastrointestinal (GI) microbiome composition and structure (Zmora et al. 2018). Therefore, future probiotics should be tailored-made to cover the needs of each individual rather than being universally consumed.

Probiotic bacteria are isolated mainly from the human gastrointestinal tract as well as from several fermented dairy products, including yogurt, cheese, and kefir. Kefir is an acidic, self-carbonated beverage made from the fermentation of kefir grains with milk. Regular consumption of kefir has been associated with gastro-protective, anti-hypertensive, and antiallergenic activities (Rosa et al. 2017). Furthermore, some strains of kefir microflora, exhibit antimicrobial, anti-inflammatory, antioxidant, and potentially anti-cancer properties (Rosa et al. 2017; Sharifi et al. 2017). Moreover, in some cases, kefir grains demonstrated immunomodulatory activities, as well as improvement of lactose intolerance in animal models (Rosa et al. 2017). The quality and the health benefits of kefir are mainly dependent on the exact composition of the microflora of the grains, which also affects the sensory characteristics of kefir. Kefir grains microflora mainly consists of lactic acid bacteria (LAB) (L. brevis, L. plantarum, L. casei, L. paracasei, etc.), Streptococci (Streptococcus salivarius), Lactococci (Lactococcus lactis ssp. thermophilus), and yeasts (Kluyveromyces, Torulopsis, and Saccharomyces sp.) (Vardjan et al. 2013; Garofalo et al. 2015). The beneficial features mentioned in the literature lately indicate that kefir grains are a promising possible source of new microbial strains for the development of functional foods (Zheng et al. 2013; Raja et al. 2009; Cho et al. 2009; Bengoa et al. 2018).

The aim of our study was to identify and characterize a number of lactic acid bacteria isolated from a commercially available Russian kefir drink and evaluate their probiotic potential. Assessment of the probiotic potential was based on the general guidelines of WHO/FAO (FAO/WHO 2002) and included tolerance to $\mathrm{pH}$ and bile salts concentrations mimicking intestinal conditions, safety assessment, molecular genotyping and phylogenetic analysis, evaluation of adhesion properties, and antiproliferative properties in in vitro experimental systems. The isolated strains with the most promising probiotic properties might be employed in further research for the production of highly added value and innovative functional food products.

\section{Materials and methods}

\section{Isolation of LAB strains from kefir grains}

Kefir grains were obtained from a Russian kefir drink that was bought from a local market. The kefir grains were gently separated from the drink using a strainer and they were washed with sterile de Man, Rogosa, and Sharp (MRS) broth (SigmaAldrich, Taufkirchen Germany). Lactic acid bacteria were isolated from kefir grains through the following procedure. The grains $(50 \mathrm{~g})$ were aseptically weighted into filtered stomacher bags and homogenized with $250 \mathrm{~mL}(0.1 \% \mathrm{w} / \mathrm{v})$ peptone water for $3 \mathrm{~min}$. Samples were then serially diluted and $1 \mathrm{~mL}$ of dilution was incorporated into MRS agar (Sigma-Aldrich). MRS plates were incubated at $37{ }^{\circ} \mathrm{C}$ for $48 \mathrm{~h}$. Morphologically distinct colonies were isolated from the plate of kefir grain and cultivated in MRS broth (Acumedia) at $30{ }^{\circ} \mathrm{C}$ for $48 \mathrm{~h}$. All isolates were further purified by streak plating and preliminarily identified based on their morphological and staining characteristics (Gram-positive bacilli). In addition, negative catalase reaction $\left(3 \% v / v \mathrm{H}_{2} \mathrm{O}_{2}\right)$ was applied.

\section{In vitro tests simulating the human GI tract}

\section{Resistance to low $\mathrm{pH}$, pepsin, pancreatin, and tolerance to bile salts}

The isolated strains were tested for resistance to low $\mathrm{pH}$ as described previously (Plessas et al. 2017). Briefly, bacterial cells from overnight cultures $(18 \mathrm{~h})$ were collected by centrifugation at $10,000 \times g$ at $4{ }^{\circ} \mathrm{C}$ for $5 \mathrm{~min}$, washed twice with phosphate-buffered saline (PBS) (pH 7.2), and resuspended in PBS adjusted to different pH including 2.0, 3.0, and 4.0. Resistance to low $\mathrm{pH}$ was measured by counting viable colonies on MRS agar plates after an incubation period of 0 and $2 \mathrm{~h}$ at $37^{\circ} \mathrm{C}$. For resistance of the lactobacilli to pepsin and pancreatin, the bacterial cells from overnight cultures were collected by centrifugation as described above, washed twice with PBS and then resuspended either in PBS solution $\mathrm{pH} 2.0$ containing pepsin (3 mg/mL; Sigma-Aldrich), or in PBS solution $\mathrm{pH} 8.0$ containing pancreatin USP $(1 \mathrm{mg} / \mathrm{mL}$; SigmaAldrich). The viable cell populations were determined after incubation on MRS agar plates at $37{ }^{\circ} \mathrm{C}$ for 0 and $3 \mathrm{~h}$ with pepsin and 0 and $4 \mathrm{~h}$ with pancreatin, respectively. Finally, to assesses tolerance to bile salts, cells from overnight cultures were centrifuged, washed twice with PBS buffer, and 
resuspended in PBS solution ( $\mathrm{pH} 8.0)$, containing $0.5 \%(w / v)$ bile salts. Resistance was assessed in terms of viable colony counts and enumerated after incubation at $37{ }^{\circ} \mathrm{C}$ for 0 and $4 \mathrm{~h}$ reflecting the time spent by food in the small intestine. All experiments were performed in triplicates and the results are presented as average values plus standard deviations.

\section{Resistance to synthesized antibiotics}

Antibiotics resistance was determined by the gradient diffusion method using M.I.C. Evaluator® strips. Ten common antibiotics were used (amoxycillin, ampicillin, amoxycillin/ clavulanic acid, clindamycin, erythromycin, gentamicin, metronidazole, tetracycline, tigecycline, and vancomycin) in concentration ranged from 0.015 to $256 \mu \mathrm{g} / \mathrm{mL}$. Evaluator strips were placed on the surface of Mueller-Hinton agar plates already inoculated with $10^{7} \mathrm{CFU} / \mathrm{mL}$ bacterial cells (McFarland turbidity index) and incubated at $37{ }^{\circ} \mathrm{C}$ for $24 \mathrm{~h}$ in microaerophilic conditions. The results were expressed in term of Minimum Inhibitory Concentration (MIC) $(\mu \mathrm{g} / \mathrm{mL})$. Three replicates per strain were conducted. L. plantarum ATCC 14917 was used as a reference strain.

\section{Bacterial strains and culture conditions}

L. casei ATCC 393 and L. plantarum ATCC 14917 were obtained from ATCC (LGC Standards, Middlesex, UK). L. paracasei $\mathrm{K} 5$ was recently isolated from Greek feta-type cheese in our lab (Plessas et al. 2017). All strains were grown anaerobically at $37^{\circ} \mathrm{C}$ on MRS broth (Sigma-Aldrich).

\section{DNA extraction, PCR amplification, and phylogenetic organization}

Genomic DNA was isolated using a genomic isolation kit NucleoSpin Tissue (Macherey Nagel, Düren, Germany) following the manufacturer's instructions. The concentration and the purity of the extracted DNA were measured at Nanodrop Spectrophotometer 2000. PCR reactions were carried out as reported before (Plessas et al. 2017). The primers P1 and P2 were described by Klijn et al. (1991). The reactions were analyzed by electrophoresis on $1 \%(w / v)$ agarose gels stained with $0.5 \mu \mathrm{g} / \mathrm{mL}$ ethidium bromide, visualized under UV illumination and photographed with a digital camera (GelDoc EQ system, Biorad, Segrate, Italy). The PCR products were purified using a PCR extraction kit (Macherey-Nagel) and sent for sequencing to VBCBiotech, Austria. The obtained DNA sequences were searched in the GenBank database using the BLAST program. Sequences of the top BLAST hits were aligned with the 16S rRNA gene sequence of the isolated strain of interest using the Clustal W program
(www.ebi.ac.uk/Tools/msa/clustalw2). Phylogenetic trees were then constructed using the neighbor-joining method within the MEGA 6 software.

\section{Species-specific multiplex PCR}

Species-specific multiplex PCR was performed as reported before (Plessas et al. 2017). Primers PAR, CAS, RHA, and CPR were described by Ventura et al. (2003). The reactions were analyzed by electrophoresis on $1 \%(w / v)$ agarose gels stained with $0.5 \mu \mathrm{g} / \mathrm{mL}$ ethidium bromide, visualized under UV illumination, and photographed with a digital camera (GelDoc EQ system, Biorad).

\section{Cancer cell lines}

The human colon adenocarcinoma cell line HT-29 was purchased from the American-Type Culture Collection (ATCC). Cells were maintained under sterile conditions at $37^{\circ} \mathrm{C}, 5 \%$ $\mathrm{CO}_{2}$ in a humidified atmosphere, and cultured in RPMI-1640 medium supplemented with $10 \%$ heat-inactivated fetal bovine serum, $100 \mathrm{U} / \mathrm{mL}$ penicillin, and $100 \mu \mathrm{g} / \mathrm{mL}$ streptomycin (all from Biosera, Boussens, France).

\section{Assessment of bacterial adhesion by quantitative analysis}

The quantitative analysis of bacterial adhesion to HT-29 cells was performed as reported by Saxami et al. (2016). Briefly, $3 \times 10^{5}$ cells/well were seeded in 24-well culture plates. Bacterial cultures were grown in MRS, overnight at $37{ }^{\circ} \mathrm{C}$, $10^{8}$ bacterial cells were added to each well, with each strain being tested in tetraplicates. Following co-incubation at $37{ }^{\circ} \mathrm{C}$ for the indicated times $(2$ and $4 \mathrm{~h})$, the cells were washed three times with PBS, lysed with $1 \%$ Triton X-100 (SigmaAldrich), and the lysates were serially diluted, plated on MRS agar, and incubated at $37^{\circ} \mathrm{C}$ for $72 \mathrm{~h}$. Adhesion values $(\%)$ were calculated as follows: $\%$ adhesion $=(\mathrm{VB} / \mathrm{VA}) * 100$, where VA is the initial viable count of bacteria tested, and VB is the viable bacteria count obtained from the HT-29 cells, at the end of the experiment.

\section{Preparation of conditioned medium}

For the preparation of the conditioned medium $(\mathrm{CM})$, the strains were grown in MRS broth (Sigma-Aldrich) at $37^{\circ} \mathrm{C}$ for $16 \mathrm{~h}$. At late-log phase of growth $\left(10^{9} \mathrm{CFU} / \mathrm{mL}\right)$, the cultures were diluted to sterile PBS (Biosera) and centrifuged at $4000 \times g$ for $15 \mathrm{~min}$. Then, the cultures were used to inoculate RPMI- 1640 containing $10 \%$ FBS and $25 \mathrm{mM}$ Hepes (all from Biosera) and were grown anaerobically for $24 \mathrm{~h}$ at $37^{\circ} \mathrm{C}$. Culture supernatants were collected by centrifugation at $4000 \times \mathrm{g}$ for $15 \mathrm{~min}$ and filtered twice through a $0.22-\mu \mathrm{m}$ pore size filter. 


\section{Cell proliferation assay}

The anti-proliferative effects of lactobacilli were determined on HT-29 cells by sulforhodamine B (SRB) colorimetric assay as described previously (Saxami et al. 2016). Briefly, HT-29 cells were seeded in 96-well microplates at a density of $6 \times$ $10^{3}$ cells per well. After the incubation period with live lactobacilli (24 and $48 \mathrm{~h}$ ) or conditioned medium (48 and $72 \mathrm{~h})$, cells were fixed with $10 \%(w / v)$ trichloroacetic acid (Sigma-Aldrich) and stained with $0.4 \%(w / v)$ SRB (SigmaAldrich) for $30 \mathrm{~min}$, after which the excess dye was removed by washing repeatedly with $1 \%(v / v)$ acetic acid (Scharlau, Barcelona, Spain). The bound dye was dissolved in $10 \mathrm{mM}$ Tris base (Sigma-Aldrich) and the absorbance was determined at $570 \mathrm{~nm}$ using a microplate reader. Cells treated with normal culture medium (untreated) were used as control. The percent cellular survival was calculated using the formula:

[( sample $\mathrm{OD}_{570}-$ media blank $\left.\mathrm{OD}_{570}\right) /$

$\left(\right.$ mean control $\mathrm{OD}_{570}-$ media blank $\left.\left.\mathrm{OD}_{570}\right)\right] \times 100$

\section{RNA extraction and CDNA synthesis}

Total RNA was extracted from HT-29 cells using RNAiso Plus (Takara, Saint-Germain-en-Laye, France) based on manufacturer's protocol. The concentration and quality of the extracted RNA were assessed spectrophotometrically and by agarose gel electrophoresis. cDNA was synthesized from $1 \mu \mathrm{g}$ total RNA by using PrimeScript 1st Strand cDNA Synthesis Kit (Takara) according to manufacturer's instructions.

\section{Quantitative PCR}

Real-time PCR was performed on a StepOne PCR System in MicroAmp® Fast Optical 48-Well Reaction Plates (both from Thermo Fisher Scientific, Waltham, USA) using the KAPA SYBR ${ }^{\circledR}$ FAST qPCR Kit (Kapa Biosystems, Wilmington, USA) according to manufacturer's instructions under the following conditions: $95^{\circ} \mathrm{C}$ for $3 \mathrm{~min}$ followed by 40 cycles of $95^{\circ} \mathrm{C}$ for $15 \mathrm{~s}$ and $60^{\circ} \mathrm{C}$ for $1 \mathrm{~min}$. The housekeeping gene $b$ actin was used as an internal control for normalization. Each reaction was performed in duplicates and each experiment included two non-template controls. The sequences of $B c l-2$, Bcl-xL, Survivin, cyclin A, cyclin B1, cyclin B2, and b-actin primers are shown in Table S1. Primer specificity was verified by performing a melting curve analysis. For the relative quantification of transcripts the formula $\mathrm{RQ}=2^{-\Delta \Delta \mathrm{Ct}}$ was used.

\section{Statistical analysis}

Graphical representations of the data were performed using GraphPad Prism. Statistical analysis was performed using
IBM® SPSS ${ }^{\circledR}$ v20 (IBM Corp. Armonk, NY, USA). Results are represented as the mean \pm SD. Statistical differences were analyzed by ANOVA with Fisher's LSD post hoc application. A $p$ value of less than 0.05 was considered statistically significant.

\section{Results}

\section{Isolation of lactic acid bacterial strains and assessment of their probiotic potential}

Initially, 48 strains were isolated from kefir grains. Thirty-nine strains were categorized to the genus Lactobacillus. The isolated LAB strains were screened in a series of established in vitro tests for probiotic potential such as (i) resistance to low $\mathrm{pH}$, (ii) resistance to pepsin and pancreatin, (iii) tolerance to bile salts, and (iv) antibiotic resistance. L. plantarum ssp. plantarum ATCC 14971 was employed in the above in vitro tests as a reference probiotic strain, as reported in previous studies (Wang et al. 2016; Plessas et al. 2017). The outcome showed that ten of these strains displayed probiotic potential. The ten strains that showed resistance to $\mathrm{pH} 3.0$ and $\mathrm{pH} 4.0$ are presented on Table 1. Notably, strains SP2 and SP5 displayed adequate viability to $\mathrm{pH} 2.0$, comparable to the reference strain. Concerning resistance to pepsin and pancreatin and tolerance to bile salts, strains SP2 and SP5 again exhibited the best scores and the achieved viabilities were near to the respective values of the reference strain (Table 1).

Accordingly, Table 2 presents the MIC $(\mu \mathrm{g} / \mathrm{mL})$ results of the ten strains, as well the MIC of L. plantarum ATCC 14917 (reference strain) against ten common synthesized antibiotics. It is evident that all lactobacilli were resistant to vancomycin (MIC $>256 \mu \mathrm{g} / \mathrm{mL}$ ) and tetracycline (MIC $>4 \mu \mathrm{g} / \mathrm{mL}$ ). Additionally, six strains were resistant to clindamycin (MIC $>1 \mu \mathrm{g} / \mathrm{mL}$ ) and seven were resistant to erythromycin (MIC > $1 \mu \mathrm{g} / \mathrm{mL}$ ). MIC ranged from 2.41 to $5.78 \mu \mathrm{g} / \mathrm{mL}$ for amoxicillin, $0.18-2.67 \mu \mathrm{g} / \mathrm{mL}$ for amoxicillin-clavulanic acid, 0.28 $2.15 \mu \mathrm{g} / \mathrm{mL}$ for ampicillin, $3.30-10.07 \mu \mathrm{g} / \mathrm{mL}$ for gentamycin, $44.8-256 \mu \mathrm{g} / \mathrm{mL}$ and above for metronidazole, and finally, $0.15-0.79 \mu \mathrm{g} / \mathrm{mL}$ for tigecycline, respectively. Notably, strains SP2 and SP5 showed the lowest MIC values for ampicillin, ampicillin, clindamycin, tetracycline, and tigecycline.

\section{Molecular characterization and phylogenetic analysis of strains SP2 and SP5}

LAB strains SP2 and SP5 recorded the highest scores in the conducted in vitro tests; likewise, were chosen for further study. Firstly, to characterize strains SP2 and SP5 at specieslevel, a variable region of the 16S rRNA gene was amplified, sequenced, and BLAST analysis was performed to reveal the 


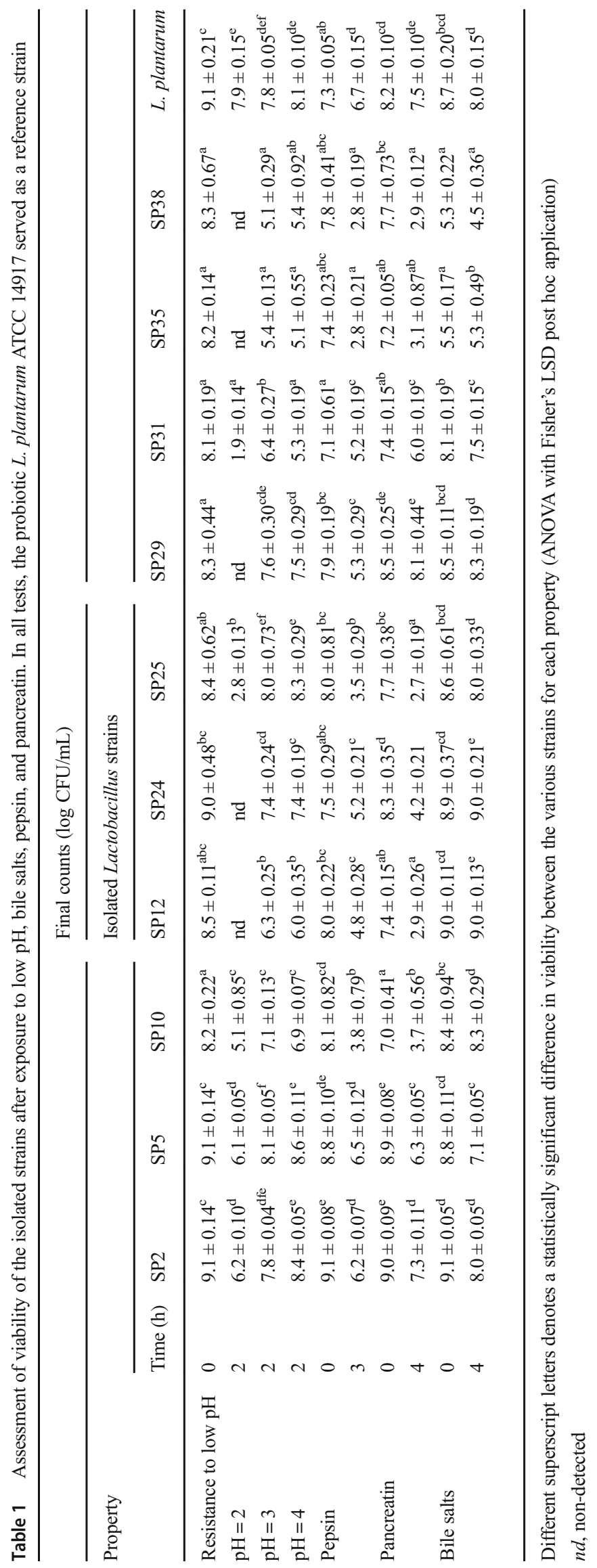




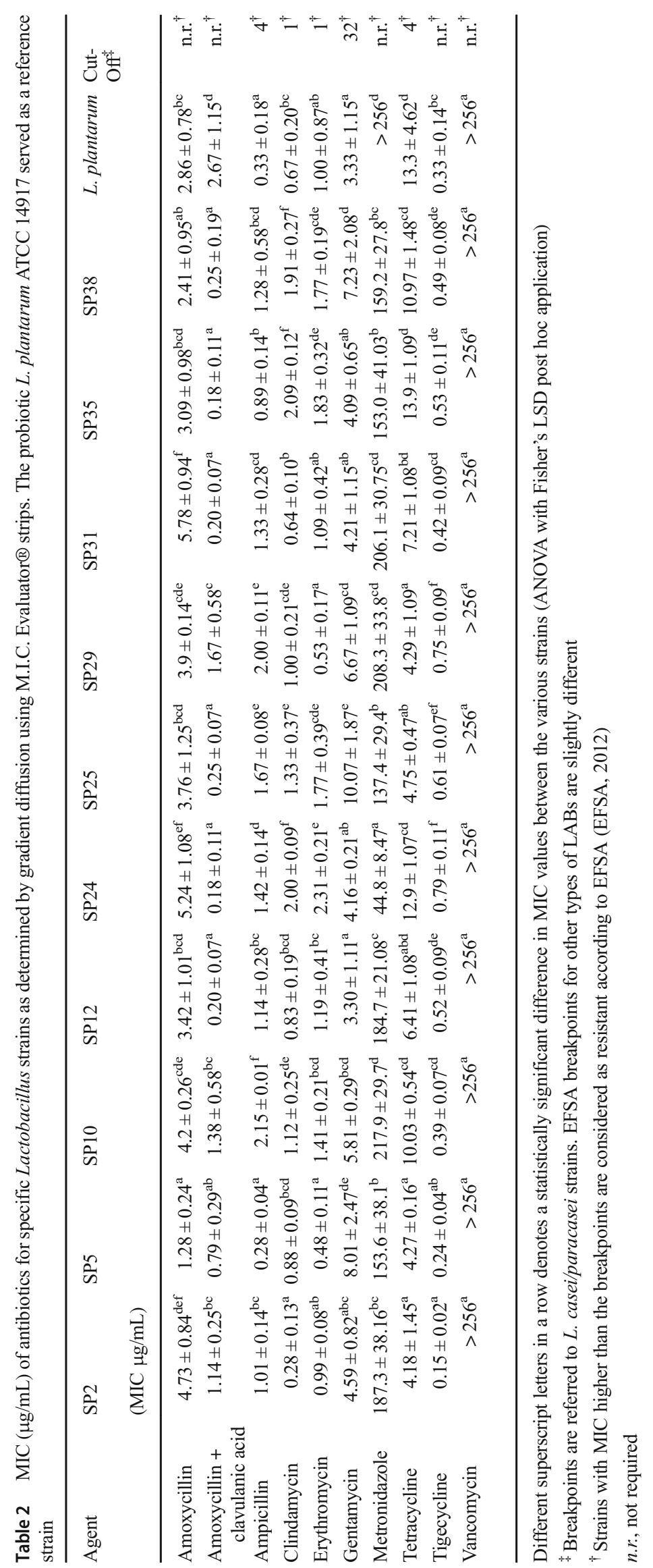


most similar sequences and species. It was found that strain SP2 shared $99 \%$ similarity to Pediococcus pentosaceus species, whereas the strain SP5 shared 99\% similarity to Lactobacillus casei and Lactobacillus paracasei species. For discrimination of the two species, a second PCR assay was then performed for strain SP5, utilizing species-specific primer sets based on the tuf gene (Ventura et al. 2003). As shown in Fig. 1, strain SP5 displayed the distinctive pattern of $L$. paracasei species, generating two amplicons at $240 \mathrm{bp}$ and $520 \mathrm{bp}$, respectively. Therefore, strain SP5 was identified as belonging to the species of $L$. paracasei and it was named L. paracasei SP5. The phylogenetic relationships of $L$. paracasei SP5 and P. pentosaceus $\mathrm{SP} 2$ are presented in Fig. S1.

\section{Evaluation of adhesion ability of $P$. pentosaceus SP2 and $L$. paracasei SP5 on HT-29 colon cancer cells}

To determine the adhesion capacity of $P$. pentosaceus SP2 and L. paracasei SP5 to HT-29 colon cancer cell line, quantitative analysis was performed. L. casei ATCC 393 was used as a reference sample. Our results showed that the adherence capacities of both strains are similar to the well-characterized probiotic strain L. casei ATCC 393. In particular, after $2 \mathrm{~h}$ of co-incubation, the adhesion rates of $P$. pentosaceus SP2 and L. paracasei SP5 were approximately $40 \%$ (Fig. 2a). Increased adhesion rates were documented for both strains after $4 \mathrm{~h}$ of co-incubation with the cancer cells (Fig. 2b).

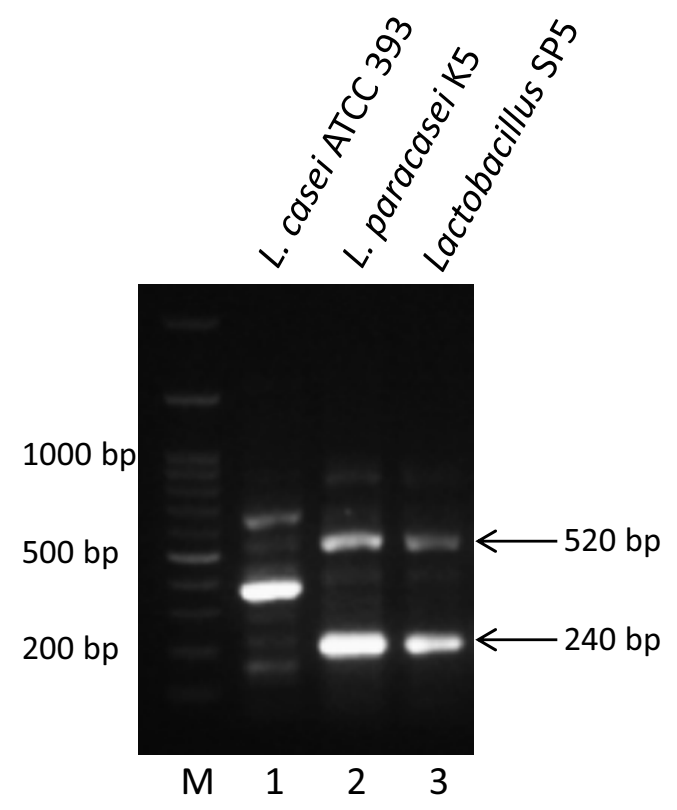

Fig. 1 Species-specific multiplex PCR for Lactobacillus SP5. Agarose gel electrophoresis of $\mathrm{PCR}$ products from multiplex PCR with the primers CAS, PAR, RHA, CPR, and DNA from pure cultures of $L$. casei ATCC 393 (line 1), L. paracasei K5 (line 2), and Lactobacillus SP5 (line 3). M: 100 bp DNA marker

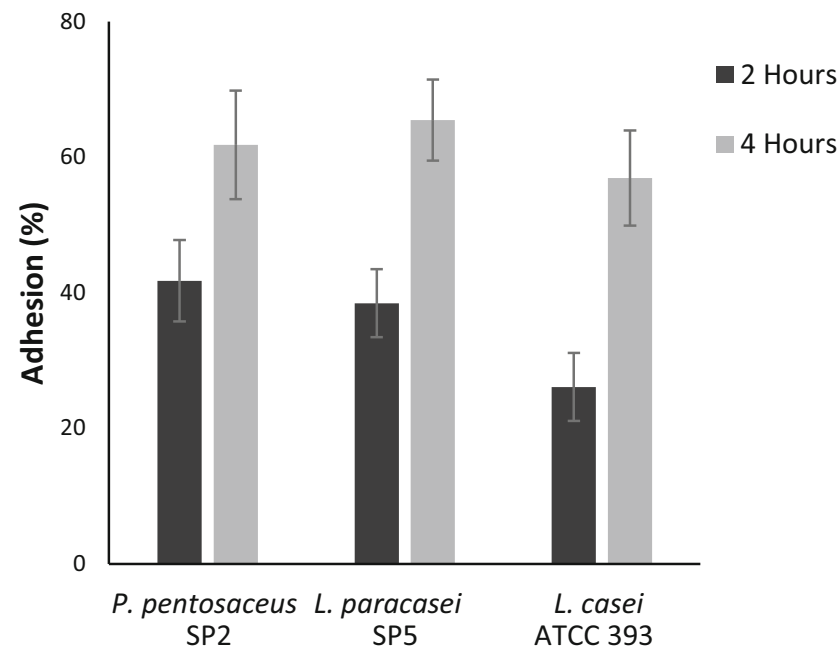

Fig. 2 Assessment of the adhesion ability of P. pentosaceus SP2 and L. paracasei SP5 to HT-29 cells by quantitative analysis. HT-29 cells were incubated with $10^{8} \mathrm{CFU} / \mathrm{mL}$ of $P$. pentosaceus SP2, L. paracasei SP5, or L. casei ATCC 393 (as reference strain) for a 2 and b 4 h. Cells were lysed with $1 \%$ Triton X-100 and the lysates were serially diluted and plated on MRS agar. Adhesion was expressed as the ratio of the number of bacterial cells counted to HT-29 cells to the number of bacterial cells added initially. The data presented are the mean \pm standard deviation of three independent experiments performed in duplicates

\section{Viable $P$. pentosaceus SP2 and $L$. paracasei SP5 cells reduce proliferation of $\mathrm{HT}-29$ cells}

To assess the anti-proliferative properties of $P$. pentosaceus SP2 and $L$. paracasei SP5 in vitro, SRB assay was employed in two time-points (24 and $48 \mathrm{~h}$ ) and at two concentrations of viable cells $\left(10^{7}\right.$ and $\left.10^{8} \mathrm{CFU} / \mathrm{mL}\right)$ in HT-29 human colon carcinoma cells (Fig. 3). L. casei ATCC 393 was used as a reference strain. Both strains exhibited a significant $(P<0.05)$ decrease of HT-29 growth in a time- and concentration-dependent manner. Specifically, treatment of cancer cells with $10^{8} \mathrm{CFU} / \mathrm{mL}$ P. pentosaceus SP2 cells for $48 \mathrm{~h}$ caused an up to $80 \%$ reduction of cell survival. Similar results were recorded for $L$. paracasei SP5. Notably, treatment with L. casei ATCC 393 resulted in a lower inhibitory effect on the survival of HT-29 cell line (Fig. 3).

\section{$P$. pentosaceus SP2 and L. paracasei SP5 induce downregulation of anti-apoptotic genes and over-expression of cyclin A gene on HT-29 cells}

To gain more insight into the anti-proliferative effects of strains $P$. pentosaceus SP2 and L. paracasei SP5, the expression levels of apoptosis and cell cycle-related genes were studied by qPCR analysis. HT-29 cells were treated for 6 and $12 \mathrm{~h}$ with $10^{8} \mathrm{CFU} /$ $\mathrm{mL} P$. pentosaceus SP2 or $L$. paracasei SP5 cells and the mRNA levels of Bcl-2, Bcl-xL, Survivin, cyclin A, B1, and B2 were analyzed. As shown in Fig. $4 \mathrm{a}$ and $\mathrm{b}$, treatment with $P$. pentosaceus $\mathrm{SP} 2$ and $L$. paracasei $\mathrm{SP} 5$ resulted in significant reduction of $B c l-2$ and $B c l-x L$ mRNA levels. Moreover, the two 
Fig. 3 Time- and dose-dependent anti-proliferative effect of

$P$. pentosaceus SP2 and L. paracasei SP5 on HT-29 cells for a, c 24 and b, d 48 hours. L. casei ATCC 393 (LC) served as reference strain. The antiproliferative effect was determined by the SRB assay. Data shown are the mean \pm SD of three independent experiments performed in duplicates. U: untreated cells. *Significantly different from untreated cells (control) $(P<0.05)$
24 hours
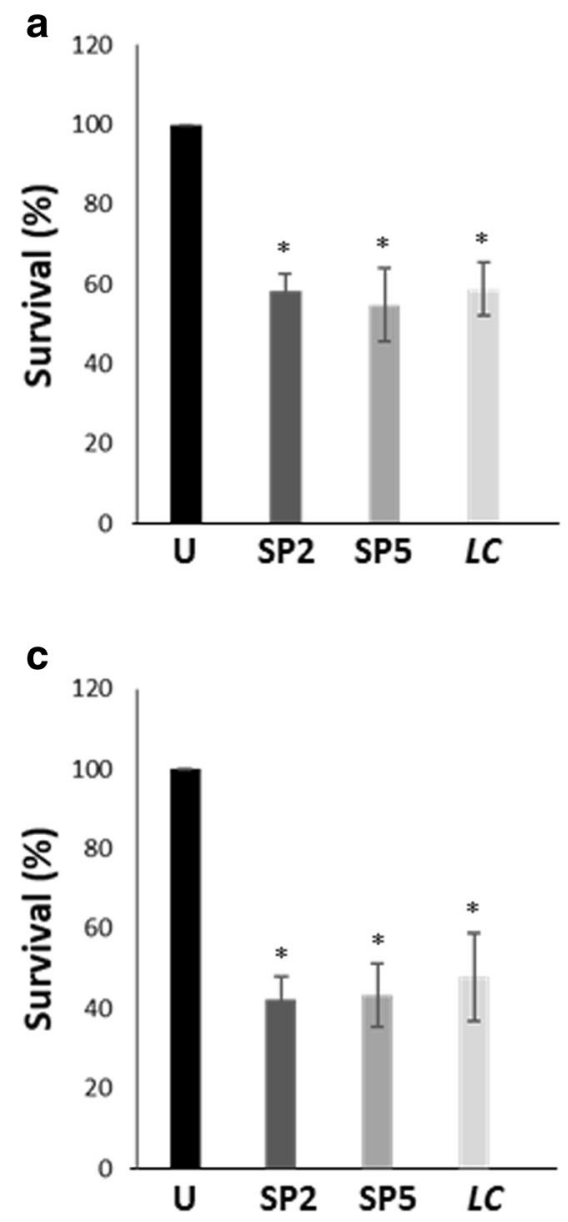

48 hours

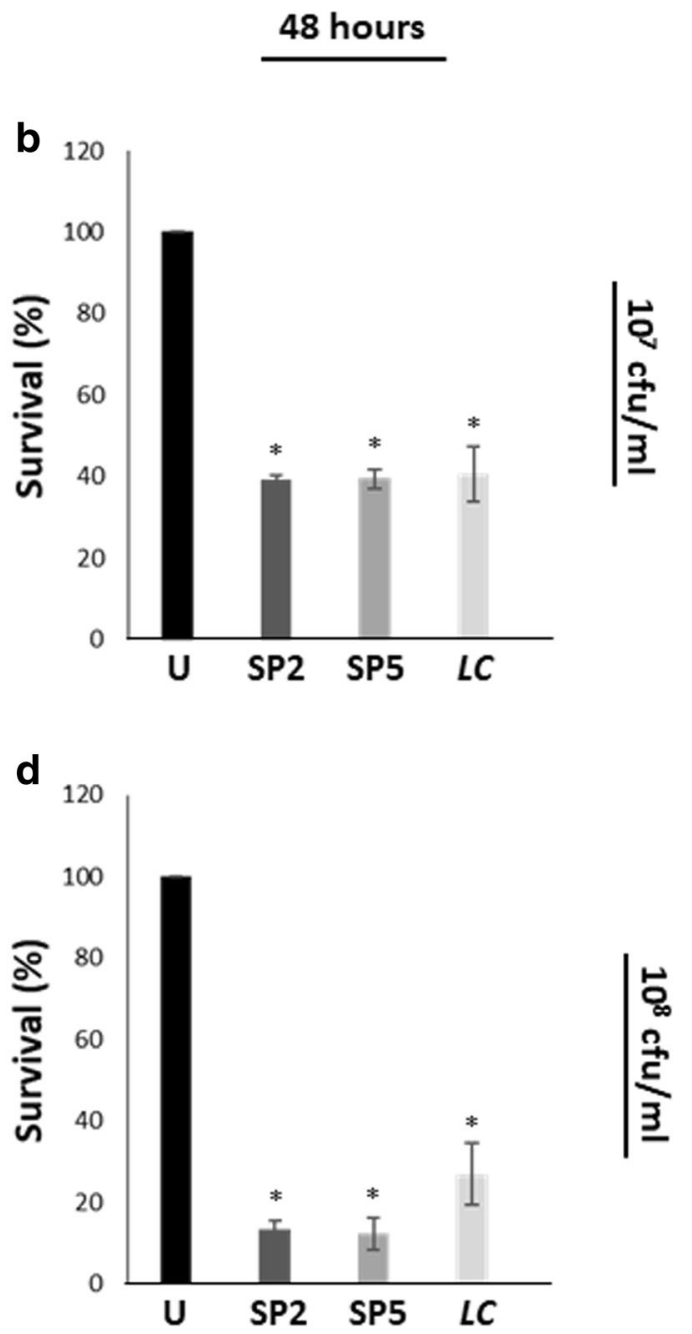

strains induced strong upregulation of cyclin $A$ expression levels compared to the control cells (Fig. 4c, d).

\section{Conditioned media of $P$. pentosaceus SP2 and $L$. paracasei SP5 exert anti-proliferative effects of HT-29 cells}

The effect of the conditioned media of $P$. pentosaceus SP2 and L. paracasei SP5 on HT-29 cell survival was presented in Fig. 5. Treatment of HT-29 cells with undiluted CM of the two strains for $48 \mathrm{~h}$ resulted in an approximately $60 \%$ reduction of cell survival. A further reduction was observed following treatment of cancer cells for $72 \mathrm{~h}$. Of note, a similar reduction was recorded for the reference strain L. casei ATCC 393.

\section{Discussion}

Kefir is a popular probiotic drink that is made from the fermentation of kefir grains with any type of pasteurized milk. Kefir grains are a complex and multifunctional culture that have been employed in various fermented systems such as bread, cheese, and milk as well as pomegranate juice and other non-alcoholic beverages (Mantzourani et al. 2014; Sabokbar and Khodaiyan 2015). The complex microbiological association of kefir grains is responsible for the high numbers of metabolites that exhibit significant health-promoting effects, such as anti-microbial, antioxidant, anti-proliferative, anti-inflammatory, and anti-mutagenic activities (Rosa et al. 2017; Sharifi et al. 2017). Likewise, kefir grains have been considered as a significant source for the isolation of probiotics microorganisms (Bengoa et al. 2018; Koh et al. 2018). In this context, we used established in vitro screening protocols to select and characterize probiotic strains from a commercially available Russian kefir drink. Initially, 48 bacterial strains were isolated, while 39 of them were categorized to the genus Lactobacillus. Evaluation of the probiotic potential of these isolates was performed, including resistance to low $\mathrm{pH}$, tolerance 
6 Hours

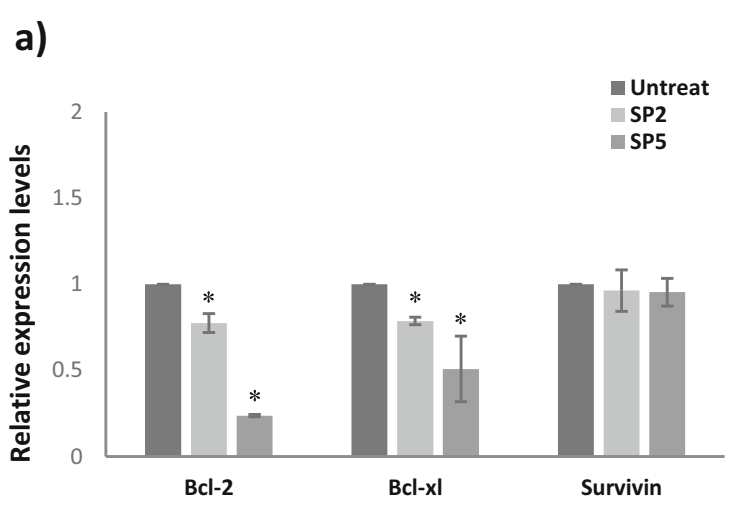

c)

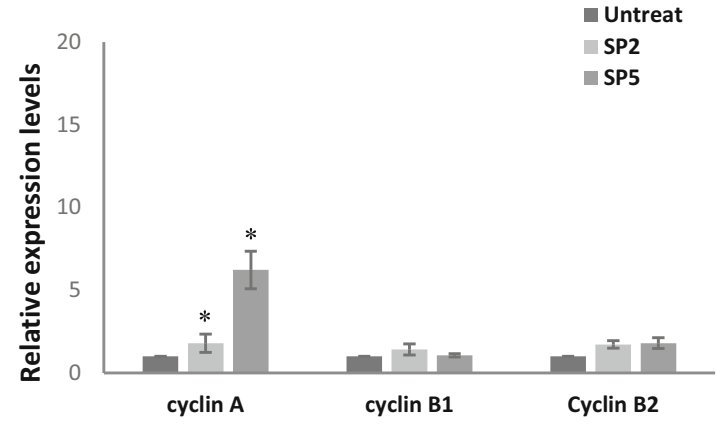

Fig. 4 P. pentosaceus SP2 and L. paracasei SP5 induce downregulation of anti-apoptotic genes and over-expression of cell cycle-related genes. HT-29 cells were treated with $10^{8} \mathrm{CFU} / \mathrm{mL} P$. pentosaceus SP2 or L. paracasei SP5 cells for a, $\mathbf{c} 6 \mathrm{~h}$ or $\mathbf{b}, \mathbf{d} 12 \mathrm{~h}$ and quantitative PCR was performed to determine the mRNA levels of a, b $B c l-2, B c l-x L$, Survivin and c, d cyclin A, B1,B2. The expression levels of Bcl-2, Bcl-

to pepsin and pancreatin and bile salts as well as safety assessment involving antibiotic susceptibility to select the strains that display the most promising probiotic properties for further studies.

The $\mathrm{pH}$ of the gastric juice is considered as a significant criterion of probiotic performance. Candidate probiotic strains should withstand at least $\mathrm{pH} 3.0$ or even lower. In the present study, six isolates retained their viability in high levels at $\mathrm{pH} 3$, whereas strains SP2 and SP5 displayed the best performance at $\mathrm{pH} 2$ (Table 1). These data are in agreement with previous studies demonstrating that potentially probiotic LAB were able to retain their viability when exposed to $\mathrm{pH}$ ranges from 2.0 to 4.0 (Argyri et al. 2013; Plessas et al. 2017). Resistance to pepsin and pancreatin and tolerance to bile salts are also considered as prerequisites for probiotic efficacy. The production of pepsin is stimulated by the release of hydrochloric acid in the stomach and induces protein digestion. Pancreatin, on the other hand, is produced in the pancreas and contributes to lipid metabolism. Bile salts are synthesized in the liver from cholesterol and also play an essential role in digestion and absorption of fats. The mean intestinal bile concentration is
12 Hours

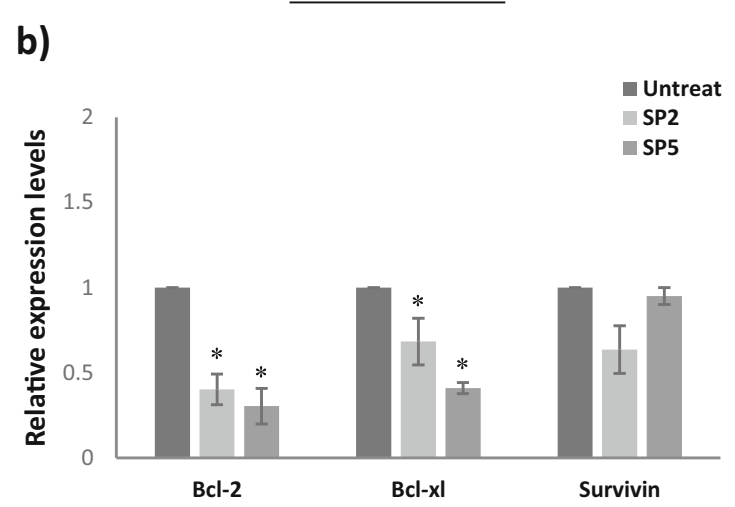

d)

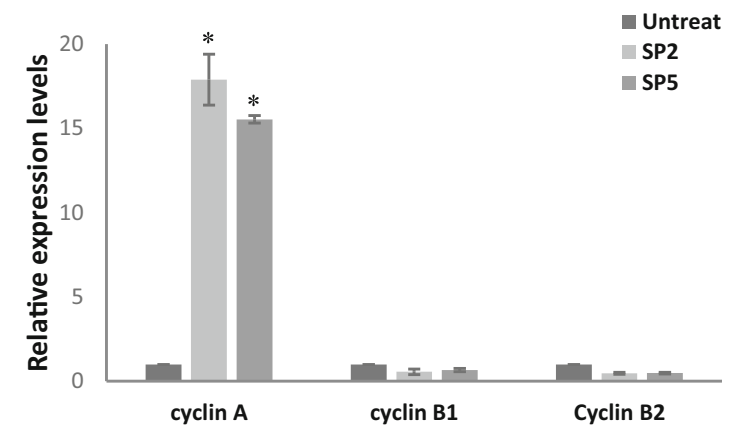

$x L$, Survivin, cyclin $A, B 1$, and $B 2$ were normalized to those of b-actin, while the untreated cells served as a reference sample. For the quantification, the formula $R Q=2^{-\Delta \Delta c t}$ was used. Data shown are the mean $\pm S D$ of three independent experiments in duplicates. *Significantly different from control (untreated cells) $(P<0.05)$

approximately $0.5 \%(w / v)$ and the staying time for food in the small intestine is around 4 to $6 \mathrm{~h}$. Accordingly, LAB have to tolerate the presence of the digestive enzymes of the stomach and the small intestine for growth, adhesion to the GI tract and subsequently, efficient probiotic action (Ouwehand et al. 2001; Argyri et al. 2013; Plessas et al. 2017). We observed that strains SP2 and SP5 were able to survive in high levels after incubation with pepsin, pancreatin, or bile salts, respectively (Table 1).

A crucial step during the in vitro assessment of any potential probiotic strain is the examination of its resistance profile against antibiotics since there is always the possibility of various resistance genes to be transferred in the gut microflora. Therefore, in this study, isolated LAB strains were tested for their susceptibility against 10 common antibiotics with different modes of action on microbial cells. Amoxicillin with or without clavulanic acid, ampicillin, and vancomycin are all inhibitors of cell wall synthesis. Clindamycin, erythromycin, gentamycin, tetracycline, and tigecycline breaks down or inhibits the synthesis of proteins while metronidazole disrupts the nucleic acid formation. An inherent resistant to 
Fig. 5 Conditioned media of P. pentosaceus SP2 and L. paracasei SP5 inhibit growth of HT-29 cells in a time- and dose-dependent manner. HT-29 cells were cultured for a, $\mathbf{c} 48 \mathrm{~h}$ or b, $\mathbf{d} 72 \mathrm{~h}$ in the presence of CM from $P$. pentosaceus SP2 or L. paracasei SP5, a, b at dilution ration $1: 2$ and $\mathbf{c}, \mathbf{d}$ undiluted $(\mathrm{C}$, D). The $\mathrm{CM}$ of the reference strain L. casei ATCC 393 (LC) was also examined. Data shown are the mean $\pm \mathrm{SD}$ of three independent experiments performed in duplicates. U: untreated cells. *Significantly different from untreated cells (control) $(P<0.05)$
48 hours

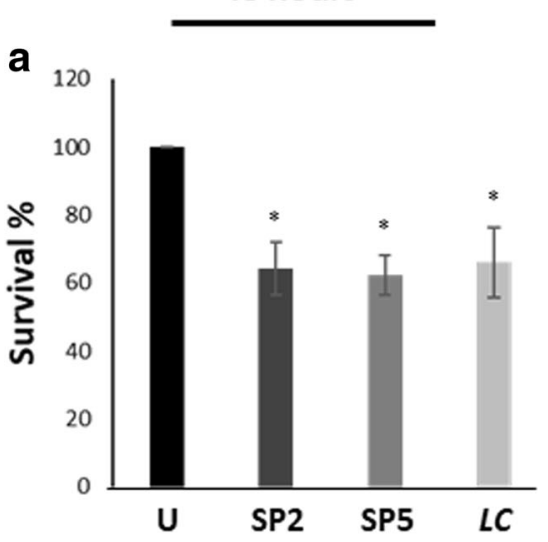

C

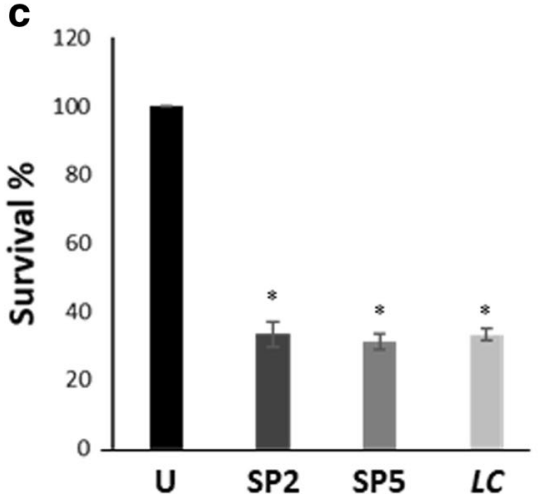

72 hours
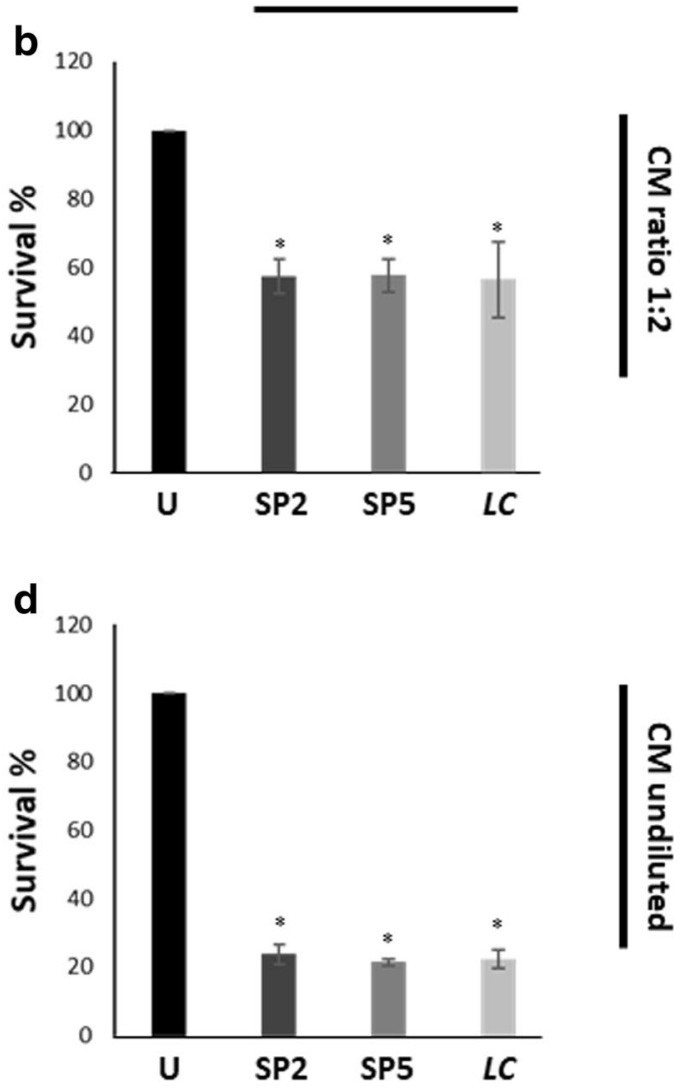

vancomycin and metronidazole similar to our results has been reported in earlier studies (Klare et al. 2007; Plessas et al. 2017). Lactobacilli, Pediococci and Leuconostoc spp. are considered resistant to vancomycin, which is an inhibitor of cell wall synthesis and as it is suggested, this resistance is a natural property for the above species arose by the presence of Dalanine:D-alanine ligase-related enzymes (Elisha and Courvalin 1995). In fact, this property has been used to distinct lactobacilli from other Gram-positive bacteria. Similarly, a natural or "intrinsic" resistance of lactobacilli to metronidazole has also been reported (Danielsen and Wind 2003). Additionally, in our study, a shared resistance to tetracycline was observed by all LAB strains. Such a resistance has also been reported previously (Drago et al. 2013). However, the resistance to these particular antibiotics does not possess any risk of resistance genes transmission by a horizontal manner, since according to EFSA, bacterial strains carrying intrinsic resistance (per se) present a minimal risk for horizontal spread and thus may be used as a feed additive (EFSA 2012). Nevertheless, for any potential probiotic strain presented for commercial use, further investigation by PCR analysis is needed for the detection (or absence) of even more specific antibiotic genes (Drago et al. 2013).
As LAB strains SP2 and SP5 recorded the highest scores in the conducted in vitro tests, they were chosen for further studies. Firstly, genotypic identification of the two strains was performed by partial $16 \mathrm{~S}$ rRNA gene sequencing, BLAST analysis, and species-specific multiplex PCR assay. The two strains were confirmed to be Pediococcus pentosaceus SP2 and Lactobacillus paracasei SP5. Several P. pentosaceus strains have demonstrated health-promoting properties. For example, it has been shown that $P$. pentosaceus LI05 is effective against Clostridium difficile infection in a mouse model (Xu et al. 2018), whereas $P$. pentosaceus LP28 downregulates the expressions of specific genes related to fatty acid metabolism in hepatic cells and exerts anti-obesity effects in high-fat diet-induced obese mice (Zhao et al. 2012). Similarly, several studies have presented probiotic properties of specific L. paracasei strains (Dang et al. 2018; Shi et al. 2018).

Adhesion of probiotic bacteria to the intestinal epithelium is a necessity to probiotic action. Adhesion may lead to transient and distinct colonization of the GI tract, immunomodulation, production of antimicrobial substances, and exclusion of pathogens by competing of their binding sites in the epithelium (Saxami et al. 2012; Chen et al. 2018). L. casei ATCC 393 is a probiotic strain, commonly used for the production of 
fermented dairy and non-dairy (Sidira et al. 2015) food products. The adherence capacity of $L$. casei ATCC 393 has been well-documented (Saxami et al. 2012; Sidira et al. 2015). In our study, similar levels of adhesion to HT-29 colon cancer cells were recorded for $P$. pentosaceus SP2 and $L$. paracasei SP5 and the reference strain $L$. casei ATCC 393, a result enhancing their probiotic potential.

The anti-tumoral effects represent another important parameter of probiotic action. It has been demonstrated that L. rhamnosus GG caused significant inhibition of proliferation of Caco-2 and HT-29 colon cancer cells (Orlando et al. 2016). In addition, both gastric (HGC-27) and colon (DLD-1) cancer cell lines were sensitive to growth inhibition and apoptotic cell death caused by L. paracasei IMPC2.1 and L. rhamnosus GG treatment (Orlando et al. 2012). Moreover, it has been shown that $L$. casei ATCC 393, displayed a significant antiproliferative effect on murine (CT-26) and human (HT-29) colon carcinoma cell lines in vitro as well as a strong reduction in tumor volume of syngeneic mice (Tiptiri-Kourpeti et al. 2016). Similarly, we have shown recently, that $L$. paracasei $\mathrm{K} 5$, a LAB strain isolated from feta-type cheese, exerts growth inhibitory effects on Caco-2 cell line, through induction of apoptosis and upregulation of proapoptotic-related genes (Chondrou et al. 2018). Here, we recorded a significant decrease of HT-29 cell growth after treatment of cancer cells with $P$. pentosaceus SP2 or L. paracasei SP5. Furthermore, real-time PCR analysis showed downregulation of $\mathrm{Bcl}-2$ and $B c l-x L$, two major anti-apoptotic genes, and over-expression of $\operatorname{cyclin} A$, a critical mediator of the G1-S transition, indicating a potential deregulation of cell cycle and induction of apoptosis. Indeed, over-expression of cyclin $A$ has been shown to cause double strand DNA damage and a delay to the S phase progression (Tane and Chibazakura 2009). Future experiments, including flow cytometry and analysis at protein level by immunoblotting will elucidate the molecular and cellular signaling pathways involved.

Live probiotic bacteria used for the production of fermented food products are Generally Recognized as Safe (GRAS) by the Food and Drug Administration (FDA). However, certain populations are potentially at risk, including cancer patients that undergo chemotherapy or radiation, pregnant women, and patients with structural heart disease (Doron and Snydman 2015). Moreover, probiotic efficacy is also dependent on the conditions of the bacterial culture and the conditions in consumer product matrices (Marco and Tachon 2013), as well as on the composition of the host gut microbiota (Zmora et al. 2018). In recent years, there has been an upsurge in research into the properties of cell-free supernatants and conditioned media of certain probiotic bacteria. Accordingly, it has been demonstrated that cell-free supernatants from probiotic L. casei ATCC 334 and L. rhamnosus GG attenuate cell invasion of the human colon carcinoma cell line HCT-116 by reducing the activity of matrix metalloproteinase- 9 and the levels of the tight junction protein zona occludens-1 (Escamilla et al. 2012). Similarly, we have shown recently, that $\mathrm{CM}$ of the probiotic strains L. pentosus B281 and L. plantarum B282, inhibited proliferation of Caco-2 cells through induction of a G1 arrest of the cell cycle and downregulation of specific cyclin genes (Saxami et al. 2017). An elegant study demonstrated that ferrichrome isolated from the CM of $L$. casei ATCC 334 exerted anti-cancer properties both in vitro and in a mouse xenograft model (Konishi et al. 2016). Here, we showed that the CM of P. pentosaceus SP2 and L. paracasei SP5 caused significant reduction of cancer cell proliferation in vitro in a time- and concentration-dependent manner. Our future research will focus on identifying the mechanisms of action and the probiotic-derived factors involved in the observed activity.

In conclusion, in the present study, we isolated a number of lactic acid bacteria from a commercially available Russian kefir drink and evaluated their probiotic potential in a series of established in vitro tests. The strains that displayed the best probiotic properties were molecularly assigned as $P$. pentosaceus $\mathrm{SP} 2$ and $L$. paracasei SP5, respectively. Both strains exerted substantial adherence on human colon cancer cells as well as significant anti-proliferative properties. Future studies, including evaluation of the technological properties and assessment of the health-promoting effects in animal models, will further elucidate the probiotic properties and verify the potential of the two strains for the development of novel functional food products.

\section{Compliance with ethical standards}

Conflict of interest The authors declare that they have no conflicts of interest.

\section{References}

Argyri A, Zoumpopoulou G, Karatzas KA, Tsakalidou E, Nychas GJ, Panagou E et al (2013) Selection of potential probiotic lactic acid bacteria from fermented olives by in vitro tests. Food Microbiol 33: 282-291. https://doi.org/10.1016/j.fm.2012.10.005

Bengoa AA, Llamas MG, Iraporda C, Dueñas MT, Abraham AG, Garrote GL (2018) Impact of growth temperature on exopolysaccharide production and probiotic properties of Lactobacillus paracasei strains isolated from kefir grains. Food Microbiol 69:212-218. https://doi. org/10.1016/j.fm.2017.08.012

Bermudez-Brito M, Plaza-Díaz J, Muñoz-Quezada S, Gómez-Llorente C, Gil A (2012) Probiotic mechanisms of action. Ann Nutr Metab 61: 160-174. https://doi.org/10.1159/000342079

Campana R, van Hemert S, Baffone W (2017) Strain-specific probiotic properties of lactic acid bacteria and their interference with human intestinal pathogens invasion. Gut Pathog 9(12). https://doi.org/10. 1186/s13099-017-0162-4

Chen S, Cao P, Lang F, Wu Z, Pan D, Zeng X et al (2018) Adhesionrelated immunomodulatory activity of the screened Lactobacillus plantarum from Sichuan pickle. Curr Microbiol 9. https://doi.org/ $10.1007 / \mathrm{s} 00284-018-1580-3$ 
Cho YJ, Lee HG, Seo KH, Yokoyama W, Kim H (2009) Antiobesity effect of prebiotic polyphenol-rich grape seed flour supplemented with probiotic kefir-derived lactic acid bacteria. J Agric Food Chem 66:12498-12511. https://doi.org/10.1021/acs.jafc.8b03720

Chondrou P, Karapetsas A, Kiousi DE, Tsela D, Tiptiri-Kourpeti A, Anestopoulos I et al (2018) Lactobacillus paracasei K5 displays adhesion, anti-proliferative activity and apoptotic effects in human colon cancer cells. Benefic Microbes 0:1-10

Dang F, Jiang Y, Pan R, Zhou Y, Wu S, Wang R et al (2018) Administration of Lactobacillus paracasei ameliorates type 2 diabetes in mice. Food Funct 9:3630-3639. https://doi.org/10.1039/ c8fo00081f

Danielsen M, Wind A (2003) Susceptibility of lactobacillus spp. to antimicrobial agents. Int J Food Microbiol 82:1-11. https://doi.org/10. 1016/S0168-1605(02)00254-4

Del Carmen S, de LeBlanc AM, Miyoshi A, Rocha CS, Azevedo V, LeBlanc JG (2011) Potential application of probiotics in the prevention and treatment of inflammatory bowel diseases. Ulcers 84165113. https://doi.org/10.1155/2011/841651

Deshpande G, Rao S, Patole S, Bulsara M (2010) Updated meta-analysis of probiotics for preventing necrotizing enterocolitis in preterm neonates. Pediatrics 125:921-930. https://doi.org/10.1542/peds.2009-1301

Doron S, Snydman DR (2015) Risk and safety of probiotics. Clin Infect Dis 60:S129-S134. https://doi.org/10.1093/cid/civ085

Drago L, Mattina R, De Vecchi E, Toscano M (2013) Phenotypic and genotypic antibiotic resistance in some probiotics proposed for medical use. Int J Antimicrob Agents 41:396-397. https://doi.org/10. 1016/j.ijantimicag.2012.11.015

EFSA/FEEDAP (2012) Guidance on the assessment of bacterial susceptibility to antimicrobials of human and veterinary importance. EFSA J 10:2740-2749

Elisha BG, Courvalin P (1995) Analysis of genes encoding D-alanine: Dalanine ligase-related enzymes in Leuconostoc mesenteroides and lactobacillus spp. Gene 152:79-83. https://doi.org/10.1016/03781119(95)98166-D

Escamilla J, Lane MA, Maitin V (2012) Cell-free supernatants from probiotic Lactobacillus casei and Lactobacillus rhamnosus GG decrease colon cancer cell invasion in vitro. Nutr Cancer 64:871878. https://doi.org/10.1080/01635581.2012.700758

FAO/WHO (2002) Guidelines for the evaluation of probiotics in food. Report of a joint FAO/WHO Working Group on drafting guidelines for the evaluation of probiotics in food. London, Ontario, Canada. ftp://ftp.fao.org/docrep/fao/009/a0512e/a0512e00.pdf . Accessed April 30 and May 1

Garofalo C, Osimani A, Milanović V, Aquilanti L, de Filippis F, Stellato $\mathrm{G}$ et al (2015) Bacteria and yeast microbiota in milk kefir grains from different Italian regions. Food Microbiol 49:123-133. https:// doi.org/10.1016/j.fm.2015.01.017

Granato D, Branco G, Gomes Cruz A, de Assis Fonseca Faria J, Shah N (2010) Probiotic dairy products as functional foods. Compr Rev Food Sci Food Saf 9:455-470. https://doi.org/10.1111/j.15414337.2010.00120.x

Howarth GS, Wang H (2013) Role of endogenous microbiota, probiotics and their biological products in human health. Nutrients 5:58-81. https://doi.org/10.3390/nu5010058

Klare I, Konstabel C, Werner G, Huys G, Vankerckhoven V, Kahlmeter G et al (2007) Antimicrobial susceptibilities of Lactobacillus, Pediococcus and Lactococcus human isolates and cultures intended for probiotic or nutritional use. J Antimicrob Chemother 59:900912. https://doi.org/10.1093/jac/dkm035

Klijn N, Weerkamp AH, de Vos WM (1991) Identification of mesophilic lactic acid bacteria by using polymerase chain reaction-amplified variable regions of 16S rRNA and specific DNA probes. Appl Environ Microbiol 57:3390-3393

Koh WY, Utra U, Ahmad R, Rather IA, Park YH (2018) Evaluation of probiotic potential and anti-hyperglycemic properties of a novel
Lactobacillus strain isolated from water kefir grains. Food Sci Biotechnol 27:1369-1376. https://doi.org/10.1007/s10068-0180360-y

Konishi H, Fujiya M, Tanaka H, Ueno N, Moriichi K, Sasajima J et al (2016) Probiotic-derived ferrichrome inhibits colon cancer progression via JNK-mediated apoptosis. Nat Commun 7:12365. https:// doi.org/10.1038/ncomms 12365

Mantzourani I, Plessas S, Saxami G, Alexopoulos A, Galanis A, Bezirtzoglou E (2014) Study of kefir grains application in sourdough bread regarding rope spoilage caused by Bacillus spp. Food Chem 143:17-21. https://doi.org/10.1016/j.foodchem.2013.07.098

Marco ML, Tachon S (2013) Environmental factors influencing the efficacy of probiotic bacteria. Curr Opin Biotechnol 24:207-213. https://doi.org/10.1016/j.copbio.2012.10.002

Orlando A, Refolo MG, Messa C, Amati L, Lavermicocca P, Guerra V (2012) Antiproliferative and proapoptotic effects of viable or heatkilled Lactobacillus paracasei IMPC2.1 and Lactobacillus rhamnosus GG in HGC-27 gastric and DLD-1 colon cell lines. Nutr Cancer 64:1103-1111. https://doi.org/10.1080/01635581. 2012.717676

Orlando A, Linsalata M, Russo F (2016) Antiproliferative effects on colon adenocarcinoma cells induced by co-administration of vitamin K1 and Lactobacillus rhamnosus GG. Int J Oncol 48:2629-2638. https://doi.org/10.3892/ijo.2016.3463

Ouwehand AC, Tuomola EM, Tölkkö S, Salminen S (2001) Assessment of adhesion properties of novel probiotic strains to human intestinal mucus. Int J Food Microbiol 64:119-126. https://doi.org/10.1016/ S0168-1605(00)00440-2

Plessas S, Nouska C, Karapetsas A, Kazakos S, Alexopoulos A, Mantzourani I et al (2017) Isolation, characterization and evaluation of the probiotic potential of a novel Lactobacillus strain isolated from feta-type cheese. Food Chem 226:102-108. https://doi.org/ 10.1016/j.foodchem.2017.01.052

Raja A, Gajalakshmi P, Mohamed Mahroop Raja M, Mohamed Imran M (2009) Effect of lactobacillus lactis cremoris isolated from kefir against food spoilage bacteria. Am J Food Technol 4:201-209. https://doi.org/10.3923/ajft.2009.201.209

Rivera-Espinoza Y, Gallardo-Navarro Y (2010) Non-dairy probiotic products. Food Microbiol 27:1-11. https://doi.org/10.1016/j.fm. 2008.06.008

Rosa DD, Dias MMS, Grześkowiak ŁM, Reis SA, Conceição LL, Peluzio MDCG (2017) Milk kefir: nutritional, microbiological and health benefits. Nutr Res Rev 30:82-96. https://doi.org/10.1017/ S0954422416000275

Sabokbar N, Khodaiyan F (2015) Characterization of pomegranate juice and whey based novel beverage fermented by kefir grains. J Food Sci Technol 52:3711-3718. https://doi.org/10.1007/s13197-014$1412-9$

Saxami G, Ypsilantis P, Sidira M, Simopoulos C, Kourkoutas Y, Galanis A (2012) Distinct adhesion of probiotic strain Lactobacillus casei ATCC 393 to rat intestinal mucosa. Anaerobe 18:417-420. https:// doi.org/10.1016/j.anaerobe.2012.04.002

Saxami G, Karapetsas A, Lamprianidou E, Kotsianidis I, Chlichlia A, Tassou CC et al (2016) Two potential probiotic lactobacillus strains isolated from olive microbiota exhibit adhesion and antiproliferative effects in cancer cell lines. J Funct Foods 24:461471. https://doi.org/10.3920/BM2016.0202

Saxami G, Karapetsas A, Chondrou P, Vasiliadis S, Lamprianidou E, Kotsianidis I, Ypsilantis P et al (2017) Potentially probiotic lactobacillus strains with anti-proliferative activity induce cytokine/ chemokine production and neutrophil recruitment in mice. Benefic Microbes 8:615-623. https://doi.org/10.3920/BM2016.0202

Sharifi M, Moridnia A, Mortazavi D, Salehi M, Bagheri M, Sheikhi A (2017) Kefir: a powerful probiotic with anticancer properties. Med Oncol 34(183). https://doi.org/10.1007/s12032-017-1044-9 
Shi Y, Cui X, Gu S, Yan X, Li R, Xia S et al (2018) Antioxidative and probiotic activities of lactic acid bacteria isolated from traditional artisanal milk cheese from Northeast China. Probiotics Antimicrob Proteins. https://doi.org/10.1007/s12602-018-9452-5

Sidira M, Kourkoutas Y, Kanellaki M, Charalampopoulos D (2015) In vitro study on the cell adhesion ability of immobilized lactobacilli on natural supports. Food Res Int 76:532-539. https://doi.org/10. 1016/j.foodres.2015.07.036

Szajewska H, Kołodziej M (2015) Systematic review with meta-analysis: Lactobacillus rhamnosus GG in the prevention of antibioticassociated diarrhoea in children and adults. Aliment Pharmacol Ther 42:1149-1157. https://doi.org/10.1111/apt.13404

Tane S, Chibazakura T (2009) Cyclin a overexpression induces chromosomal double-strand breaks in mammalian cells. Cell Cycle (Georgetown, Tex) 8(23):3900-3903. https://doi.org/10.4161/cc.8. 23.10071

Tiptiri-Kourpeti A, Spyridopoulou K, Santarmaki V, Aindelis G, Tompoulidou E, Lamprianidou E et al (2016) Lactobacillus casei exerts anti-proliferative effects accompanied by apoptotic cell death and up-regulation of TRAIL in colon carcinoma cells. PLoS One 11: e0147960. https://doi.org/10.1371/journal.pone.0147960

Vardjan T, Mohar Lorbeg P, Rogelj I, Čanžek Majhenič A (2013) Characterization and stability of lactobacilli and yeast microbiota in kefir grains. J Dairy Sci 96:2729-2736. https://doi.org/10.3168/ jds.2012-5829

Ventura M, Canchaya C, Meylan V, Klaenhammer TR, Zink R (2003) Analysis, characterization, and loci of the tuf genes in lactobacillus and bifidobacterium species and their direct application for species identification. Appl Environ Microbiol 69:6908-6922. https://doi. org/10.1128/AEM.69.11.6908-6922.2003
Wang P, Wu Z, Wu J, Pan D, Zeng X, Cheng K (2016) Effects of salt stress on carbohydrate metabolism of Lactobacillus plantarum ATCC 14917. Curr Microbiol 73:491-497. https://doi.org/10. 1007/s00284-016-1087-8

Weese JS, Martin H (2011) Assessment of commercial probiotic bacterial contents and label accuracy. Can Vet J 52:43-46

Xu Q, Gu S, Chen Y, Quan J, Lv L, Chen D et al (2018) Protective effect of Pediococcus pentosaceus LI05 against Clostridium difficile infection in a mouse model. Front Microbiol 9(2396). https://doi.org/ 10.3389/fmicb.2018.02396

Zhao X, Higashikawa F, Noda M, Kawamura Y, Matoba Y, Kumagai T et al (2012) The obesity and fatty liver are reduced by plant-derived Pediococcus pentosaceus LP28 in high fat diet-induced obese mice. PLoS One 7:e30696. https://doi.org/10.1371/journal.pone.0030696

Zheng Y, Lu Y, Wang J, Yang L, Pan C, Huang Y (2013) Probiotic properties of lactobacillus strains isolated from Tibetan kefir grains. PLoS One (7):e69868. https://doi.org/10.1371/journal.pone. 0069868

Zmora N, Zilberman-Schapira G, Suez J, Mor U, Dori-Bachash M, Bashiardes S et al (2018) Personalized gut mucosal colonization resistance to empiric probiotics is associated with unique host and microbiome features. Cell 174:1388-1405. https://doi.org/10.1016/ j.cell.2018.08.041

Publisher's note Springer Nature remains neutral with regard to jurisdictional claims in published maps and institutional affiliations. 